\title{
La realidad, la fotografía y la imagen digital
}

Alberto J. L. Carrillo Canán (BUAP)

acarrillo_mx@yahoo.com

La discusión filosófica sobre el problema de las relaciones entre la realidad y su representación a través de imágenes nos remonta hasta la crítica platónica de la pintura como copia de una copia, ya que, consabidamente, Platón concebía a la realidad empírica como copia de la realidad superior de las ideas, por lo que la pintura de una mesa, venía a ser la copia de una mesa sensible que a su vez era la copia de la idea de la mesa. Por su parte, las religiones también han dado un amplio campo para la discusión de la relación entre imagen y realidad, en este caso, la realidad de lo divino. Sin embargo, el paso de la imagen pictórica a la imagen fotográfica abrió un nuevo horizonte para la discusión de la relación entre la realidad y su representación, dado que con ella se experimentó por primera vez lo que se debe ser llamado la representación tecnológica de la realidad como un tipo de represtación completamente nuevo. La representación tecnológica se amplió inopinadamente con la aparición del cine y, sin embargo, en las últimas dos décadas entramos de lleno en una nueva ampliación de las tecnológicas de representación de la realidad mediante imágenes gracias al desarrollo de las tecnologías digitales hechas posibles por las computadoras. ${ }^{1}$ En este trabajo nos concentraremos en examinar las relaciones entre la realidad y su representación fotográfica y digital, dejando de lado al cine pero haciendo referencia constante a la pintura. Es justamente el auge presente de la imagen digital y sus complejas relaciones con la realidad lo que hace urgente rediscutir el ya milenario problema de la relación entre la realidad y su representación visual a través de semejanzas. En esta discusión tendremos que rozar inevitablemente el asunto estético de la ilusión, implícito en el problema de la representación de la realidad a través de la semejanza perceptiva.

\footnotetext{
${ }^{1}$ Por supuesto, la representación tecnológica a la que nos referimos aquí es la representación por medio de semejanzas, excluyendo otro tipo de imágenes que básicamente codifican ciertas variables para representarlas gráficamente, como es el caso de los sismógrafos, los manómetros, los voltímetros y de una miríada de otros instrumentos, los cuales también generan representaciones tecnológicas de la realidad pero no por medio de semejanzas.
} 


\section{La fotografía y la realidad}

Un excelente punto de inicio para nuestra discusión lo dan las famosas tesis del teórico cinematográfico André Bazin, por lo que en un primer momento resulta necesario reconstruir algunas de sus ideas principales sobre el carácter de la imagen fotográfica. ${ }^{2}$

La invención de la fotografía fue el resultado de numerosos experimentos acumulados que satisficieron el anhelo de lograr la reproducción plástica perfecta de un objeto mediante técnicas desarrolladas ex professo. Obviamente, los primeros antecedentes de las técnicas de reproducción se encuentran en productos de antiguas civilizaciones para las cuales la reproducción plástica era un procedimiento mágico: reproducir algo ya existente era conservarlo - la máscara egipcia del cadáver momificado "conservaba" la faz del difunto -, mientras que producir una figura plana o tridimensional era anticipar una realidad, por ejemplo, la imagen propiciaba la caza (Lascaux) o la fertilidad (Venus de Willendorf) (WC1 10). La evolución paralela del arte y la civilización liberó a las artes plásticas de su función mágica original, de tal manera que tanto el deseo de "preservar artificialmente la apariencia corporal" (WC1 9) de un ente "raptándolo del flujo temporal para mantenerlo el dominio de la vida" (WC1 9), como la práctica mágica propiciatoria, dieron paso al ideal profano de la reproducción plástica perfecta. Así, según Bazin, “(...) en el siglo XV la pintura occidental comenzó a despreocuparse de la expresión de una realidad espiritual (...) para tender a la imitación más o menos completa del mundo exterior." (WC1 11) Este es el problema estético del realismo en las artes plásticas: el ideal de la reproducción del "exterior" o de la naturaleza, ideal que en tanto tal había surgido ya por vez primera entre los pintores y los escultores de la Grecia Clásica. ${ }^{4}$

Por lo que hace a la imagen bidimensional, Bazin señala que la aparición de la fotografía liberó a la pintura de su incesante búsqueda de la reproducción perfecta, es decir, la liberó de la "obsesión por el realismo" (WC1 12) de una manera por demás revolucionaria. Por una parte, la forma dejó de tener un valor imitativo y pudo ser devorada por el color (cfr. WC1 16); por otra, la fotografía va más allá de la mera "semejanza hasta la identidad misma

\footnotetext{
${ }^{2}$ Las ideas de Bazin a las que nos referimos están contenidas casi en su totalidad en su famoso ensayo $L a$ ontología de la imagen fotográfica.

${ }^{3}$ Para la bibliografía y las abreviaturas véase la lista al final de este texto. Las cursivas al interior de una cita son nuestras a menos que expresamente se indique que son del autor del texto citado.

${ }^{4}$ Recuérdese aquí la anécdota contada por Plinio el Viejo sobre la disputa entre Zeuxis (nacido aprox. en el 464 a. C.) y Parrasios para decidir quien era mejor pintor. Zeuxis pintó unas uvas que al ser develadas engañaron a los gorriones, después de lo cual Zeuxis pidió a Parrasios que corriera el velo de su pintura para poder apreciarla, resultando que la cortina era pintada, a continuación Zeuxis declaró vencedor a Parrasios porque si bien él, Zeuxis, había engañado a los gorriones, Parrasios lo había engañado a él. Cierta o no, la anécdota atestigua la vigencia del ideal realista como marca de excelencia pictórica ya en la Grecia Clásica.
} 
[de la imagen] con su modelo" (WC1 16). En términos pictóricos lo primero lleva a la pintura abstracta (por ejemplo Rothko), mientras que lo segundo es la evidencia de la aparición de un medio nuevo, totalmente diferente de la pintura, un medio nuevo en el que la reproducción no es simple semejanza sino duplicación real: el objeto adquiere no una mera imitación sino un verdadero doble en su imagen fotográfica dado que la fotografía es "la toma de una impresión mediante la manipulación de la luz" (WC1 12), ${ }^{5}$ es decir, la fotografía es una "transferencia de la realidad de la cosa a su reproducción" (WC1 14) o, en otras palabras, "[1]a imagen fotográfica es el objeto mismo, (...) debido al proceso del que surge, comparte el ser del modelo del cual es la reproducción; ella es el modelo." (WC 14). ${ }^{6}$ Con ello se subvierte la situación mágica original de las artes plásticas: en vez de la substitución de la identidad del objeto reproducido por su imagen (cfr. WC1 10), la fotografía nos entrega la verdadera “identidad del modelo y la [su] imagen” (WC1 10). En vez de un substituto mágico de la identidad se tiene la duplicación tecnológica del modelo en su reproducción fotográfica. ${ }^{7}$

Por lo demás, dado que según Bazin el problema estético del realismo es “esencialmente la historia de la semejanza" (WC1 10), resulta natural que en el paso de la simple semejanza entre objetos a cierta identidad entre los mismos, Bazin distinga un problema ontológico implícito en el desarrollo que va desde la reproducción plástica de la realidad a su reproducción tecnológica, problema que está parcialmente oculto por el hecho de que ambas son reproducciones de la realidad. Tal vez la mejor manera de mostrar que realmente aquí hay un problema ontológico propiamente dicho es seguir la propia sugerencia de Bazin en el sentido de que "[e]l mundo estético del pintor es de diferente clase que el mundo alrededor de él (...)” (WC1 15) - ya que los límites de tal mundo estético “(...) encierran un microcosmos substancial y esencialmente diferente (...)" (WC1 15) del mundo que rodea al pintor -, mientras que, por el contrario, "[1]a fotografía en tanto tal y el objeto mismo [el modelo] comparten un ser común, a la manera de una huella digital." (WC1 15) En otras palabras, “(...) la fotografía realmente contribuye en algo al orden de la creación natural en vez de ofrecer un substituto del mismo." (WC1 15) Este es lugar en el que la estética tiene

\footnotetext{
${ }^{5}$ Como lo expresa de una manera más precisa técnicamente Dudley Andrew en su prólogo a la edición inglesa de Bazin: se trata de la "impresión" de un "patrón único de luz refleja [propio del objeto] sobre la emulsión" (WC1 xv).

${ }^{6}$ Dado que en este caso las cursivas en la cita son del autor, nosotros usamos subrayados para resaltar lo que queremos.

${ }^{7}$ Para Barthes la fotografía repite mecánicamente su motivo (cfr. CL 4).
} 
implicaciones ontológicas: la ilusión no es realidad, y lo cierto es que la fotografía no es mera ilusión. ${ }^{8}$

Queda claro que la insistencia de Bazin en que la fotografía y el objeto fotografiado tienen cierta identidad, en que comparten el ser, refiere a un orden común de la realidad, refiere al hecho de compartir o ser parte de un mundo que es completamente diferente del "mundo estético del pintor" (WC1 15), del mundo de la ilusión pictórica. Y en verdad, el mundo de la fotografía es el mismo que el mundo que rodea al pintor, es el mundo de la "creación natural" (WC1 15), expresión que, obviamente, no desconoce que una fotografía es un artefacto, algo creado por el hombre, sino que indica que la fotografía pertenece al mismo orden de realidad que su objeto o modelo. La imagen pictórica genera una ilusión de realidad, una ilusión del mundo que rodea al pintor, ofrece un mero "substituto del mismo" (WC1 15); por el contrario, la fotografía en su significado o relevancia tiene la misma importancia que tiene la "huella digital" respecto del dedo que es su modelo, la misma que tiene la huella del dinosaurio respecto del animal mismo. En otras palabras, la densidad ontológica de la fotografía no es la de la ilusión, que es en lo que reside la densidad ontológica de un pintura figurativa - el verdadero y único competidor pictórico de la fotografía, dado que la pintura abstracta pertenece a otro mundo estético que el del realismo plástico -; la densidad ontológica de la fotografía, el orden de realidad al que pertenece - independientemente de sus cualidades estéticas - es el mismo orden de realidad que el del objeto fotografiado. Por eso, como dice Bazin, "[1]a fotografía nos afecta como un fenómeno en la naturaleza (...)". (WC1 13). Siguiendo entonces la sugerencia de Bazin, podemos decir que la pintura no agrega nada al orden de la realidad sino solamente al de la ilusión, mientras que la fotografía se suma al mundo con una realidad que es del mismo orden que su modelo - como la huella del animal se suma al mundo del animal, "al de la creación natural" (WC1 15), es decir, la fotografía se suma al mundo de la realidad, no de la ilusión. En otras palabras, mientras que la realidad definitoria o esencial de la pintura no es la de ser un objeto del mundo sino la de ser una ilusión, la fotografía misma es una realidad del mundo, más acá de toda ilusión. ${ }^{9}$

\footnotetext{
${ }^{8}$ En este trabajo dejamos de lado por completo el problema de la estética fotográfica. Para esto véase la serie de artículos de Carrillo Canán A. J. L. y Gómez Mendoza L. sobre La estética fotográfica en el paso a la digitalización que aparecerán en la revista electrónica de filosofía A Parte Rei.

${ }^{9}$ Ciertamente es posible abordar el asunto de la ilusión estética plástica como un tipo particular del problema filosófico de los mundos posibles, pero esto iría mucho más allá de la simple clarificación de que, en efecto, Bazin tiene razón en su sugerencia de que la representación fotográfica en su diferencia de la reproducción pictórica no es un mero problema de las ciencias empíricas sino, además, un problema de la reflexión filosófica propiamente dicha.
} 
Por supuesto, expresiones de Bazin respecto de la fotografía, como el que es una "huella", una “impresión" (WC1 12), un "molde lumínico" (WC2 98), y otras, pueden precisarse más. Una oportunidad de lograr tal precisión es recurrir a la teoría peirceana del índice.

Apegándose a la teoría de peirceana P. Dubois nos dice que el índice es "una representación por contigüidad física del signo con su referente" (AF 42); siendo más específicos, o como diría Peirce mismo, hay una "conexión física" (EP 6) entre el signo y su “objeto" (EP 9). ${ }^{10}$ Así, por ejemplo, la dirección de la veleta está en conexión física con el viento, por lo que la orientación de la veleta indica la dirección del viento reproduciéndola. De la misma manera, las huellas del dinosaurio indican la presencia del animal en un tiempo dado en un lugar determinado. En el caso de la placa fotográfica, lo que se tiene es la "huella de una realidad" (AF 43). ${ }^{11}$ Así, discutiendo en contra de la idea de la codificación fotográfica, Pascal Bonitzer dice que una fotografía “(...) es en primer lugar una muestra directa de lo real que la química hace aparecer (...)" (citado por Dubois, AF 45).

Como lo señala Dubois, se subraya ahora la singularidad de lo real y de su "huella" (cfr. AF 45). Es justamente esta idea de la singularidad de la "huella" o del índice acoplado con una realidad igualmente singular, como toda realidad, está implícita en las declaraciones de Barthes de que "[u]na fotografía nunca se distingue de su referente (...)" (CL 5), de que “(...) la fotografía siempre lleva a su referente con ella misma" (CL 5), o bien, de que la "[1]a fotografía es literalmente una emanación del referente.” (CL 80); ${ }^{12}$ de hecho, la “(...) fotografía repite mecánicamente lo que nunca podría ser repetido existencialmente.” (CL 4) En todo esto está implícita la cualidad singular de la fotografía y de su referente: un referente corresponde a una fotografía, su fotografía. Para evitar confusiones y discusiones inútiles, digamos que el "referente" es lo que aparece frente al lente - ciertos objetos y su entorno - y que el lente puede "cubrir" desde su ubicación y orientación. El referente así definido es el

\footnotetext{
${ }^{10}$ Peirce dice: "El índice está conectado físicamente con su objeto; ambos forman una unidad orgánica." (EP 9)

${ }^{11}$ Peirce mismo dice lo siguiente: "Las fotografías (...) son en ciertos aspectos exactamente iguales a los objetos que representan. Pero esta similitud se debe a que las fotografías son producidas bajo circunstancias en las que fueron forzadas físicamente a corresponder punto por punto a la naturaleza. En ese sentido, entonces, pertenecen a (...) los signos (...) debidos a una conexión física." (EP 6).

${ }^{12}$ Véase también la formulación de Metz en el sentido de que en una fotografía “(...) el objecto mismo se imprime en la película virgen.” (FL 15)
} 
causante del arreglo lumínico que es captado por el lente y queda registrado sobre la película fotosensible $-\mathrm{o}$, en su caso, el sensor digital $-{ }^{13}$

Lo cierto es que la relación entre la fotografía y su referente es más intensa, más íntima, que la de la mera similitud. Los similares pueden ser muchos, mientras que cada fotografía es la fotografía singular irrepetible de un singular que en tanto tal es también irrepetible. ${ }^{14}$ La fotografía es, ontológicamente, algo mucho más denso, porta mucha más realidad que una similitud más o menos vaga, a saber, es una duplicación o repetición de algo, es una verdadera reproducción; y es solamente por eso que tiene un referente y también que es similar a su referente. La fotografía tiene, mediante la "conexión física" (Peirce) una relación necesaria con su referente, a diferencia la relación que proviene de la similitud. Ciertamente, la fotografía es similar a su referente, como una buena pintura figurativa es similar a su modelo, pero en la medida en la que es un huella lumínica de su referente, la fotografía es también su índice, un índice semejante a él. De acuerdo con ello, y precisando la noción de la fotografía como índice, es necesario decir que la fotografía no solamente es un índice sino que, más específicamente, es un índice icónico o bien un icono indéxico. A diferencia del símbolo (Peirce), se parece a su referente, y si se parece a este, es porque a diferencia del simple icono está conectada con él físicamente. ${ }^{15}$ Tal es la naturaleza de todo icono indéxico, en particular de la fotografía en tanto huella o impresión lumínica.

\footnotetext{
${ }^{13}$ Evidentemente, el referente así definido es relativo al lente, su ubicación y orientación, pero esto no quita ni un ápice a la objetividad de la relación entre el referente y su fotografía. Por ejemplo, el referente acotado por un lente normal de $50 \mathrm{~mm}$ será diferente del referente del gran angular de $8 \mathrm{~mm}$ en la misma ubicación y con la misma orientación; el segundo lente permite captar una porción mucho mayor del entorno, sin embargo, la captación, por diferente que pueda ser, es igualmente objetiva. Lo mismo puede decirse de las variaciones en la calidad del lente: por grandes que sean y por mucho que influyan en el resultado, la relación entre el referente y la fotografía sigue siendo igualmente objetiva. Además de los factores ya señalados están, claro, los ajustes hechos a la cámara, por ejemplo, al tiempo y a la apertura, pero también para ellos vale lo mismo: no alteran la objetividad de la relación entre el referente y la fotografía. Por supuesto eliminamos de nuestra consideración del caso de fotografías totalmente sobreexpuestas o totalmente subexpuestas que dan lugar a imágenes totalmente grises blancas o negras, es decir, iguales, para referentes distintos. Por lo demás, una definición más tradicional del referente se limitaría al objeto o motivo de la fotografía, el cual en ocasiones puede ser un tanto ambiguo por ejemplo cuando se toma una vista amplia -. Pero aún con esta definición más tradicional la situación no cambia esencialmente: en todo caso lo que está frente a la cámara tiene, dados el lente y la cámara y su ubicación y posición, una relación totalmente objetiva con la fotografía. En cualquier caso vale la tesis de Barthes ya citada arriba en el sentido de que la fotografía es literalmente una emanación del referente, una impresión del patrón único de luz correspondiente al referente (cfr. Andrew en: WC1 xv).

${ }^{14}$ Por supuesto que una fotografía puede ser duplicada indefinidamente - en papel o sobre un monitor - pero aquí entendemos por "fotografía" la clase matemática de todas las imágenes esencialmente iguales de un mismo referente. Así, todos los duplicados de una fotografía dada son la misma fotografía. Por ello Barthes afirma que "[u]na fotografía (...) nunca se distingue de su referente (...)" (CL 5) y que "[l]o que la fotografía reproduce hasta el infinito ocurrió solamente una vez: la fotografía repite mecánicamente lo que nunca podría ser repetido existencialmente." (CL 4)

${ }^{15}$ Véase la cita de Peirce en la nota de pie de página 11, en la que el mismo Peirce explica la similitud entre la fotografía y su "objeto" debido a la conexión física entre ellos.
} 
En síntesis, la fotografía en su génesis automática, es una transferencia física, de acuerdo con leyes perfectamente definidas, de lo real a la superficie de la película fotosensitiva. Este es el punto que define la especificidad de la fotografía análoga, su propiedad fundamental en términos técnicos, pero que, a su vez, tienen la profunda implicación ontológica de poner a la representación fotográfica en tanto representación en el mundo de lo real, separándola radicalmente de la representación plástica pictórica cuyo ámbito específico en tanto representación, aquel en el que adquiere sentido más allá de ser un objeto mundano, empírico, es el de la ilusión, un ámbito que por definición pertenece al de lo no real. La idea de Bazin en el sentido de que la fotografía y su modelo "comparten el ser", equivale a la idea peirceana de que en tanto índice de su referente la fotografía está en “conexión física" con él.

A partir de aquí el siguiente paso es comparar el carácter indéxico de la fotografía tradicional, análoga, con las propiedades de la fotografía digital, como punto de partida de un estudio más amplio que pretende reconocer la manera en que la fotografía digital ha cambiado el trabajo artístico plástico.

\section{La imagen digital fija}

En la primera sección de este trabajo nos concentramos en discutir la "ontología de la imagen fotográfica" y, siguiendo al teórico cinematográfico André Bazin, vimos que una primera manera de definir el ser de la imagen fotográfica era distinguiéndola de la pintura figurativa; es justamente este tipo de pintura, cuyo ser está dedicado a la ilusión estética, lo que nos permite distinguir de una manera muy clara que, en efecto, la fotografía análoga es un objeto totalmente diferente de la pintura. Mientras que la representación pictórica en general pertenece al mundo de la ilusión, la representación fotográfica está en continuidad ontológica con lo que representa, por lo que ambos pertenecen al orden de la realidad empírica. También vimos que esta continuidad ontológica, el ser compartido por la representación fotográfica y lo que representa, se puede expresar mediante la idea peirceana del índice, como algo que está en "conexión física" con lo que indica, lo que, por otra parte, no puede decirse de la pintura. Siendo, pues, la fotografía tradicional, la fotografía análoga, un icono indéxico, su orden de realidad es el mismo que el de lo fotografiado. En verdad, entre el cemento fresco de la acera en Hollywood en el que una estrella fílmica imprime su mano, por un lado, y la placa fotosensitiva en la que un objeto imprime su traza lumínica, por otro, no existe ninguna diferencia esencial: el cemento preparado ex professo para recibir la impresión de la mano de 
la estrella y la película fotosensitiva preparada ex professo para recibir la impresión lumínica de un objeto en su entorno, son exactamente lo mismo: artificios humanos preparados ad hoc para recibir una transferencia de realidad del mundo empírico. Más aún, entre el cemento fresco en Hollywood y el terreno blando en el que un T-rex imprimió su huella hace eones tampoco hay una diferencia radical; en otras palabras entre una fotografía cualquiera y un $\mathrm{T}$ rex no existe ninguna diferencia ontológica como la que sí existe entre el retrato pictórico de una persona y la fotografía de la misma persona. El retrato pictórico pasa por la representación mental, mientras que la imagen fotográfica no. La pregunta ahora, es cuál es la naturaleza, el orden de realidad de la fotografía digital en particular y el de la imagen digital fija en general.

La fotografía digital también tiene el carácter de índice icónico propio de la fotografía análoga, aunque en este caso el registro de las características del arreglo lumínico causado por el motivo fotográfico en su entorno particular - el referente - no sea sobre una película fotosensitiva sino en un sensor digital fotosensitivo; el tipo de registro es en términos tecnológicos totalmente distinto pero sigue tratándose de un registro de propiedades lumínicas generadas de manera única e inequívoca por un referente singular. No necesitamos discutir aquí la naturaleza técnica específica del registro digital sobre el sensor fotosensitivo, de la misma manera que atrás no necesitamos discutir la naturaleza técnica específica del registro químico sobre la película fotosensitiva. Lo que importa es el hecho tecnológico con consecuencias ontológicas de que también en el caso digital hay una "conexión física" (Peirce) entre el referente y la imagen resultante, sea esta impresa o desplegada sobre alguna pantalla. En otras palabras, la fotografía digital es fotografía porque tiene exactamente la misma característica esencial de ser un icono indéxico, solamente que en este caso el icono es resultado de un proceso digital mientras que el caso de la fotografía tradicional el icono es resultado de un proceso químico. Se trata de dos formas de hacer exactamente lo mismo, a saber, registrar la información lumínica "emanada" (Barthes) del referente. Por otra parte, como se indicó en la primera parte de este trabajo, existe la imagen digital que es transformada y cuando la transformación va más allá de cierto punto surge el problema teórico de qué sucede con el hecho fotográfico esencial o básico del registro de información registro de propiedades lumínicas - 


\subsection{La imagen digital y su transformación débil}

El concepto de "transformación" o "manipulación" que suele emplearse cuando se habla la imagen digital es muy vago, por lo que ahora debemos precisarlo. Existe un caso básico de transformación de la imagen que es el que mantiene el hecho de que la imagen resultante es, de cualquier manera, un registro icónico de un referente. Pongamos un ejemplo bastante elemental de una imagen "transformada" que sigue siendo un registro muy similar a los que nos interesan aquí directamente; se trata de la famosa "casa de los espejos". En una de tales casas hay espejos que devuelven la imagen de la persona que está frente a ellos alargada, ensanchada, ondulada, etc. Supongamos que se trata de una imagen alargada. Lo cierto es que en la imagen transformada de la persona se pueden reconocer la cara y los miembros, la ropa y su color; así, si aparecen ojos, aunque sean deformados, es porque la persona - como es natural - tiene ojos, si aparece con una camisa roja, aunque sea alargada, es porque la persona porta una camisa roja. Todo esto es así porque la imagen alongada sigue siendo un registro, un registro deformado pero, aún así, un registro icónico de la información lumínica generada por lo que está delante del espejo. Lo mismo vale para cualquiera de las otras imágenes especulares transformadas propias de una casa de los espejos y, esto es lo importante ahora para nosotros, lo mismo vale para todas las transformaciones digitales que siguen siendo un registro. De hecho, un caso totalmente análogo al de la casa de los espejos es el de las fotografías análogas con lentes especiales como el así llamado ojo de pescado; un lente de este tipo da un registro transformado de lo que está frente al lente pero, de todos modos, un registro.

Similarmente, el procesamiento de la imagen fotográfica digital con ayuda de software puede ser tal que se siga teniendo un registro, lo que quiere decir que también en este caso se dispone de un icono indéxico. En este rubro encontramos transformaciones tales como la conversión de una fotografía digital en color a la correspondiente fotografía en blanco y negro o en sepia, múltiples deformaciones de la misma, etc. Este tipo de procesamiento lo llamaremos débil y como resultado de él se sigue teniendo una fotografía. El procesamiento débil alcanza hasta el punto en el que conociendo la imagen original no transformada todavía no sometida al procesamiento digital - aún es posible reconocer lo que aparece en ella en la imagen ya transformada; en este caso la imagen transformada sigue siendo un icono indéxico. En la práctica este punto límite puede ser más o menos variable, pero teóricamente está bien definido: la fotografía es un registro consistente en un índice icónico, nos muestra la 
imagen indéxica de algo que podemos reconocer a partir de la imagen original, no transformada.

Mención especial merecen los llamados "filtros" de los programas de "edición de imagen" computacionales - como el famosísimo Fotoshop -. Los filtros son “opciones" en un "menú" en los programas de edición de imagen y son el análogo digital de los lentes reales ya que arrojan una imagen icónica con las características de un registro, de un índice, aunque no sean ningunos lentes. Para aclarar esto, tengamos en cuenta que todo lente implica ya una cierta transformación óptico mecánica de la información lumínica incidente sobre él, mientras que todo filtro en el software implica una transformación adicional de dicha información, solamente que dicha transformación adicional es digital y no mecánica. Para clarificar esto pensemos en el caso de la pérdida de información lumínica.

Todo lente tiene cierta "claridad" que no es total, lo que quiere decir que parte de la luz incidente sobre el lente no pasa a la película o al sensor, es decir, parte de la información lumínica proveniente del referente se pierde al cruzar el cristal del lente. Uno de los múltiples análogos digitales de la pérdida de información es el filtro llamado "posterización". En la "posterización” parte de la información lumínica que sí logró pasar a través del lente y que sí se tiene almacenada digitalmente, es descartada; la información que se descarta es cromática: muchos tonos alrededor de un tono dado son substituidos por este tono con el resultado de que la imagen resultante es "la misma" imagen que la original pero con una escala cromática tremendamente reducida, con lo que la imagen resultante tiene el aspecto de un poster serigráfico.

Análogamente un gran angular rectilíneo, digamos de $14 \mathrm{~mm}$, capta porciones del entorno muy por arriba de la horizontal de la visión normal al costo de que lo que las líneas verticales tienden a encontrarse, así por ejemplo, un edificio alto puede ser captado en toda su altura pero en vez de que su fachada aparezca como un rectángulo aparece como una pirámide trunca. Por supuesto, en un programa decente de edición de imagen aparece un "menú" de "transformaciones", y una de ellas es precisamente la de alongar la imagen de la manera que lo hace un gran angular rectilíneo.

En este sentido podemos decir que los "filtros" y otras "transformaciones" digitales tales como las deformaciones geométricas de todo tipo - son ni más ni menos que verdaderos lentes virtuales: dispositivos para el procesamiento de la información lumínica digitalizada que, a final de cuentas, va a quedar registrada después de su transformación digital, en el "archivo" correspondiente - la fotografía almacenada en la computadora -. Por supuesto, la 
posterización y múltiples otras transformaciones digitales no se pueden obtener con lentes, por lo que las transformaciones digitales equivalen a lentes virtuales que van mucho más allá de lo que pueden hacer los lentes reales. Ahora bien, lo importante del concepto de lente es que es un dispositivo completamente objetivo para el procesamiento de la información lumínica proveniente del referente fotográfico. Justamente en este sentido las transformaciones digitales de las que hablamos, las trasformaciones digitales débiles, son lentes virtuales. Y lo importante es que todo lente, real o virtual, así como la combinación de lentes, ya sean estos reales o virtuales o una mezcla de lentes reales y virtuales, arroja como resultado una imagen indéxica, un icono indéxico.

Acabamos de mencionar las combinaciones de lentes y esto nos lleva a una diferencia importante entre la imagen almacenada en un archivo digital y una fotografía impresa. El archivo digital puede ser retrabajado - vuelto a transformar - indefinidamente. Así por ejemplo, es posible aplicar varios filtros diferentes o el mismo filtro sucesivamente, sin que esta operación tenga un límite definido. En el caso de los lentes reales, en la práctica la mayoría de los "lentes" son una construcción que contiene en un mismo recipiente cilíndrico varios "grupos de lentes", es decir, grupos de verdaderas piezas de cristal individuales que se ponen unos tras otros para "sumar" sus efectos singulares en el efecto total del "lente". En ese sentido los lentes reales son una serie de transformaciones fijas en un orden fijo, mientras que los filtros y otras transformaciones digitales son "lentes" virtuales que se pueden reordenar de una manera muy libre. En la práctica, todas las fotografías digitales son el resultado de un procesamiento óptico mecánico de la información lumínica a través de varios grupos de cristales más un procesamiento digital de dicha información a través de varios filtros o de otras transformaciones digitales, sean estas poco notorias o tan notables como las de la casa de los espejos. De cualquier manera lo importante es que la imagen resultante es un icono indéxico, es decir, una fotografía en el sentido estricto de la palabra.

\subsection{La imagen digital y su transformación fuerte}

Existe, por supuesto, un procesamiento digital diferente, al que llamaremos fuerte, que da por resultado una imagen que ya no es una fotografía, es decir, ya no hay ninguna conexión o contigüidad física entre la imagen resultante y lo que esta representa icónicamente. De hecho, lo que la imagen representa icónicamente ya no pertenece al orden de la realidad empírica. ${ }^{16}$

\footnotetext{
${ }^{16}$ Recordando lo dicho al inicio de la segunda sección de nuestro trabajo, diremos ahora que mientras que el Trex y una fotografía digital pertenecen al mismo orden de realidad, la fotografía digital y la imagen resultante de una transformación digital fuerte pertenecen a diferentes órdenes de realidad.
} 
Esto, por supuesto, no es algo completamente nuevo pues era ya el caso del collage fotográfico y de la superposición obtenida a partir de fotografías análogas.

En el collage se pegan partes de diferentes fotografías por lo que si bien hay registros, el resultado total, el collage propiamente dicho, ya no corresponde a ninguna realidad, como sería en el caso de, digamos, un collage que nos mostrara un centauro; ${ }^{17}$ en este caso hay representación icónica indéxica por partes pero no total; la imagen global no es imagen (icono) de nada real. Para evitar errores es necesario señalar que incluso el collage más inocente, por ejemplo, pegar sobre un fondo fotográfico el recorte de la fotografía de una persona, es ya una imagen que no guarda ninguna continuidad ontológica con la realidad: aunque dicha persona llegue a estar parada realmente contra dicho fondo real, el collage no corresponde a ningún referente, no corresponde al referente constituido por la persona en el lugar adecuado, no es la fotografía de dicha persona en dicho lugar. Como podría decir Bazin, ningún collage agrega nada al orden de la realidad, ya que no es la huella o la impresión lumínica de nada, no hay ningún referente que le corresponda. ${ }^{18}$

Algo similar ocurre con la superposición, por ejemplo, de la imagen fotográfica de una persona frente a la imagen fotográfica de un edificio; ${ }^{19}$ en la realidad la persona no estaba frente al edificio, por ello el resultado es una representación icónica de algo que no existió, no hay - no hubo -, pues, una realidad de la cual el resultado sea un registro, es decir, la imagen resultante no tiene carácter indéxico aunque sea icónica y parezca ser un registro, un índice. ${ }^{20}$ A diferencia del collage, la superposición sí parece una fotografía, pero de todos modos no tiene un referente.

Por su fama en la historia de la fotografía y por su importancia práctica señalemos todavía aquí el caso de manipulación fotográfica consistente en quitar algo de una fotografía.

\footnotetext{
${ }^{17}$ Por supuesto, existen collages mucho más exóticos y complicados que esto.

${ }^{18}$ Ver la discusión sobre la ontología de la imagen fotográfica en la primera sección de este trabajo.

19 La superposición se logra en la fotografía análoga exponiendo cuidadosamente la misma película a dos referentes para que los dos aparezcan como uno solo registro.

${ }^{20}$ La conocida crítica a la objetividad fotográfica (por ejemplo, Fontcuberta, Kossy) partiendo del hecho bien conocido de la fotografía manipulada, es asombrosamente superficial, pues deja de lado que dicha objetividad está basada en el carácter indéxico de la fotografía, sin el cual el engaño producido por la fotografía manipulada no sería posible. El simple hecho de que se pueda uno preguntar si hay manipulación en una fotografía dada, muestra que en principio la fotografía es objetiva, indéxica. Así, frente a una pintura la pregunta en cuestión no tiene absolutamente ningún sentido, simplemente no es posible hacerla porque nadie parte de que la pintura sea un registro automático. En un contexto más amplio es totalmente evidente la carencia de fundamento a la crítica de la objetividad de la fotografía como documento. Así por ejemplo, el que se pueda falsificar la lectura de un manómetro o la gráfica de un sismógrafo no lleva a nadie a poner en cuestión los manómetros o los sismógrafos en general; análogamente, el que sea posible falsificar pinturas no lleva a nadie a declarar la muerte de la pintura como pintura. Aún suponiendo que la falsificación de una pintura o de una pieza arqueológica no pudiera ser detectada en un momento dado con un estado de la técnica dado, eso no llevaría a poner en duda el carácter documental de dichos elementos en general.
} 
Esto es un procedimiento totalmente diferente de la superposición pero podemos llamarlo aquí superposición negativa: transformando la imagen análoga se "borra" una parte de la fotografía haciendo aparecer en su lugar lo que previsiblemente se vería en la fotografía si la parte por borrar hubiera estado al momento de hacer la fotografía. ${ }^{21}$ Esta manipulación es una superposición negativa en el sentido de que el fondo se "superpone" aparte de lo que no es el fondo. Obviamente lo que aparece en la imagen manipulada no es el referente de nada aunque también en este caso dicha imagen parezca una fotografía. ${ }^{22}$

Ahora bien, la transformación digital fuerte cubre casos como los recién señalados del collage y de la superposición en la fotografía análoga, la única diferencia es que por la naturaleza digital de las imágenes, el proceso puede ser bastante más fácil de realizar y, si se quiere, el resultado realmente parece una fotografía aunque no lo sea. Como en el caso de materiales análogos, este procesamiento que hemos llamado transformación fuerte merece ser llamado manipulación. Obviamente, lo característico de la transformación fuerte o manipulación fotográfica es que la imagen transformada ya no es ninguna fotografía, ya no es el registro icónico de un referente, por más que lo pueda parecer. Nuevamente, en términos de Bazin, lo representado en la representación - la imagen manipulada - no pertenece al orden de la realidad empírica: nunca existió como referente de ninguna fotografía; en el mejor de los casos es, como en el caso de la pintura, una ilusión en el sentido estético de este término, en el peor es una ilusión en el sentido de un engaño. ${ }^{23}$

Por supuesto, existe todavía otro caso muy importante de la imagen digital fija, pero para tratarlo haremos referencia a un teórico de este tipo de imagen.

\subsection{Las transformaciones de la imagen técnica y su carácter indéxico}

Andrew Darley considera los productos de la cultura visual digital, y muestra que existen importantes diferencias en las propiedades estéticas entre la imagen digital y la fotografía análoga, incluso respecto de aquella fotografía análoga que ya había buscado recursos en el collage y la superposición, los cuales son importantes porque, como acabamos de ver, llevan a que la imagen resultante rompa con la característica esencial de la fotografía discutida arriba y que implica la relación icónica indéxica entre el fotograma y su referente - por lo que la

\footnotetext{
${ }^{21}$ Tal vez el caso más famoso en la historia de la fotografía sea la foto de Lenin dando un discurso sobre un templete a cuyo pie aparece Trotzky, fotografía que por orden de Stalin fue manipulada de tal manera que aparece todo como estaba pero ya sin Trotzky.

${ }^{22}$ En el caso señalado en la nota de pie de página anterior, de la fotografía manipulada por los estalinistas, la imagen resultante parece foto, pero no es foto de nada porque el supuesto referente no existió nunca.

23 A esto último, al engaño, pertenece, evidentemente, la fotografía de Lenin sin Trotzky resultante de la manipulación estalinista. Más abajo volveremos a la problemática de la ilusión y del engaño.
}

Comentario [AC1]: No hay que olvidar la diferencia entre el engaño por manipulación por manipulación u objetivo y el engaño por omisión o subjetivo - un tipo de ilusión -. Por ejemplo, respecto de la frescura de la piel de una persona, se puede tomar la fotografía con poca luz, de tal manera que las imperfecciones de la piel no queden registradas o bien se puede manipular la fotografía retocándola de tal manera que dichas imperfecciones desaparezcan. En el segundo caso la fotografía es un registro en el sentido estricto del término $\mathrm{y}$, sin embargo, el observador va a ser llevado a la ilusión subjetiva de que la persona es más joven de lo que en realidad es. En el primer caso la fotografía está manipulada y de esta manera objetiva - objetivamente, por acción de otro - la persona va a ser llevada también al engaño. Un cierto equivalente de esto es cuando verbalmente se omite información para que el oyente llegue a ciertas conclusiones sin que se le digan, y el caso contrario, cuando falazmente al oyente se le dicen ciertas conclusiones que no corresponden a los hechos. 
imagen ya no es, en realidad, ningún fotograma -. De manera similar, las técnicas básicas del procesamiento digital de imágenes muestran claramente una profunda alteración de la relación de la imagen fotográfica con su referente, es decir, con la dimensión de lo real y, por lo tanto, del carácter indéxico característico de la fotografía. Dichas técnicas son la composición y la sintetización digitales (cfr. VD 18). La primera, como el nombre lo indica, combina fotografías digitales reales de diferentes referentes - frecuentemente partiendo de bancos de imagen (galerías fotográficas) -, con el resultado de que lo que se ve en la fotografía no existe como un todo aunque existan - o hayan existido - sus partes -; no existe el referente global aunque existan los referentes parciales. ${ }^{24}$ Es evidente que esto cubre el caso discutido en el párrafo anterior de la transformación fuerte que es, en los hechos, una verdadera manipulación de la imagen, manipulación que lo es en la medida en que termina eliminando de la imagen resultante el carácter indéxico propio de la fotografía - ya sea análoga o digital -.

Por su parte, la sintetización digital es el proceso de creación de una imagen a partir de la nada, en ausencia de todo registro fotográfico, caso en el que, como es evidente, la ausencia de un referente para la imagen es incomparablemente más radical que en la mera composición: ya no se trata de la combinación esencialmente arbitraria de los referentes singulares en un solo referente total inexistente, sino que se trata de la generación de supuestos referentes y, por tanto, de la ausencia absoluta de todo referente verdadero. ${ }^{25}$

En ambos casos, la composición y la sintetización, la naturaleza de la imagen como registro de algún referente es profundamente subvertida. De hecho queda claro incluso que el término fotografía ya no puede ser utilizado: la fotografía no crea nada, registra (Bazin: transfiere la realidad; Barthes: la repite), mientras que tanto la combinación como la sintetización digitales producen la imagen de algo inexistente. La fotografía, análoga o

\footnotetext{
${ }^{24}$ Ciertamente, este texto presenta en lo fundamental la relación entre la fotografía y su referente como una relación en el presente, lo cual no es más que una simplificación ya que, evidentemente, lo que se fotografió es básicamente irrepetible y en sentido estricto siempre queda en el pasado, mientras que la foto queda en un presente indefinido, lo cual va siendo cada vez más notorio con las fotos "viejas", aquellas que muestran cosas que hace mucho dejaron de existir tal como se les mostró en dichas fotografías. Sobre el asunto de la fotografía como testimonio de una presencia en el pasado véase la insistencia de Barthes en la fotografía como "una emanación de una realidad pasada" (CL 88) y en que la fotografía dice "(...) solamente y de manera asertiva lo que fue (...)" (CL 85), así como, en terminología fenomenológica, en el "noema" fotográfico como "esto fue" (CL 96).

${ }^{25}$ La sintetización también recibe, en los últimos años, el nombre de animación. Aunque el término "animación" refería originalmente a procesos utilizados para dar la sensación de movimiento a imágenes fijas, el hecho de que los programas para lograr dicho movimiento también puedan ser utilizados para generar imágenes desde cero, es decir, imágenes sintetizadas, va llevando progresivamente al uso del término "animación" para las imágenes sintetizadas independientemente de la sensación de movimiento.
} 
digital, se caracteriza por que la cámara estuvo frente a su referente, es ese sentido, fue "testigo" de este y la fotografía resultante es su traza es su "traza" o "huella" luminosa (Bazin), su "emanación" (Barthes), el referente "se adhiere" a ella (CL 6). Por eso en el contexto más amplio de la imagen fija tecnológica - no pictórica -, en vez del término "fotografía" debe utilizarse el término más neutral de "imagen digital", el cual deja abierto si se trata de una imagen como registro (digital) o bien como combinación o sintetización y, por tanto de una imagen como creación.

En particular es claro que la sintetización es un producto totalmente digital porque no corresponde a ningún registro lumínico en absoluto, de tal manera que no tiene nada que ver con la cualidad indéxica definitoria de la fotografía, cualidad que, como discutimos arriba, coloca a la imagen en relación de contigüidad o conexión física con el objeto fotografiado y su entorno - el referente -. En la composición, por otro lado, aún se puede partir de un registro - personal o tomado de un banco de datos - en formato digital, y dado que se parte de verdaderas fotografías, si estas están combinadas con cierta habilidad mínima, se tiene la impresión de que la fotografía combinada es una fotografía aunque lo que muestra sea absurdo. En el caso de la sintetización, si esta es de buena calidad, también se tiene la impresión de que se está ante una fotografía aunque en este caso no exista ningún elemento de verdadera imagen fotográfica - ningún registro lumínico -; de hecho, los "animadores digitales" buscan tal efecto como la marca se su habilidad y, de esta manera, nos presentan, por ejemplo, un vaso con bebida perfectamente verosímil sin que en la imagen haya ningún elemento fotográfico en lo absoluto. En ambos casos, el de la sintetización y el de la composición, no existe referente, a pesar que la imagen tenga la apariencia que la hace indistinguible de una fotografía en el sentido restringido y propio de este término que vale en primer lugar para la fotografía análoga pero también, en segundo lugar, para la fotografía digital que no ha sido sometida a manipulación alguna.

En síntesis, la fotografía análoga y la digital tienen carácter indéxico, eso las hace el tipo de iconos específicos que son: iconos indéxicos que deben su carácter indéxico a tecnologías de registro de propiedades lumínicas del entorno generadas por el referente, propiedades que, por tanto, son información sobre el referente. Por su parte, la imagen compuesta digitalmente solo tiene carácter indéxico por partes - igual que la superposición o el collage en el caso de la fotografía análoga -, mientras que la imagen sintetizada carece absolutamente de todo carácter indéxico, aunque no, claramente, de carácter icónico ya que su interés consiste, precisamente, en parecerse a la fotografía de algo. En fin, mientras que la 
imagen fotográfica análoga o digital es un icono indéxico, la imagen sintetizada es un icono no indéxico que parece ser indéxico; por su parte la imagen análoga que utiliza el montaje o la superposición fotográficos, lo mismo que la imagen digital sometida a la composición, son un mosaico de íconos indéxicos que en ocasiones, como tal mosaico, no es ícono de nada ${ }^{26}$ y en ocasiones - composición digital, superposición análoga - suele ser un icono no indéxico de algún supuesto referente.

\section{La ontología de la imagen fija}

En esta, la sección conclusiva de nuestro trabajo, retomamos la discusión del problema de la ontología de la imagen fija para aclarar ideas que tanto en la primera como en la segunda secciones no fueron precisadas suficientemente. Ahora el tipo de realidad característico de la imagen fotográfica quedará definitivamente claro en comparación con el tipo de realidad propio de la imagen pictórica tradicional y con el tipo de realidad de la imagen digital no indéxica.

\subsection{Las huellas y la transferencia de realidad}

Retomando la muy breve discusión hecha al inicio de la segunda sección de este trabajo, diremos ahora que el que un dinosaurio haya dejado su huella en arcilla fresca hace millones de años no tiene ninguna diferencia esencial con respecto a que un perro o un gato contemporáneos dejen su huella en el cemento fresco de una acerca en construcción; tales huellas son, en ambos casos, ocurrencias casuales de acuerdo con las leyes del mundo empírico. Ahora bien, el que una estrella de Hollywood imprima su mano en el cemento fresco específicamente preparado para recoger la huella de las estrellas fílmicas, no es una ocurrencia casual del mundo físico, dado que en realidad se trata de todo un dispositivo diseñado para obtener tal resultado; sin embargo, el hecho de que en los casos del dinosaurio, del perro y del gato, la huella sea una ocurrencia casual mientras que en el caso de la huella de la estrella hollywoodense la ocurrencia sea planificada, no altera para nada el hecho de que lo que opera determinando la naturaleza del resultado - la huella, en todos los casos - es única y puramente la legalidad física. Si bien la subjetividad está presente en la construcción del dispositivo consistente en el conjunto de arreglos para producir la huella de la estrella fílmica, la subjetividad no tiene absolutamente nada que ver con la operación pura de la legalidad física que determina la huella; lo que opera es dicha legalidad y el dispositivo en cuestión simplemente la aprovecha, vale decir, pues, que la subjetividad aprovecha el automatismo de

\footnotetext{
${ }^{26}$ Piénsese por ejemplo, en alguno de los famosos collages dadaístas.
} 
la legalidad física para obtener un resultado de manera automática, objetiva. Obviamente lo mismo vale para el caso de la huella lumínica de un referente sobre la película fotosensitiva o sobre el sensor digital; ambos, la película y el sensor, son parte de dispositivos ideados por la subjetividad para aprovechar el funcionamiento automático de legalidades físicas. Ni en el caso del cemento fresco hollywoodense, ni en el caso de la película o el caso del sensor, la subjetividad es parte del resultado, en ninguno de los tres casos la subjetividad es parte del dispositivo diseñado para obtener el resultado automáticos aunque el dispositivo mismo sí sea un resultado de la subjetividad. Por eso entre las huellas del dinosaurio, las del perro o gato, la impresión de la palma de la estrella fílmica y las fotografías análoga y digital de un referente dado, no existe absolutamente ninguna diferencia en cuanto que dichos entes son resultados de la acción automática del mundo físico, una acción en que la intervención de la subjetividad en algunos de los casos es un presupuesto pero en ninguno es factor alguno en la naturaleza físico empírica del resultado. ${ }^{27}$ Las huellas, incluidas las fotografías en tanto huellas lumínicas, sean estas ocurrencias azarosas o planificadas, son resultados obtenidos por el solo funcionamiento automático de legalidades físicas. Por esta razón, dichas huellas son parte del mundo empírico tanto como lo es aquello de lo que son huellas; en términos de Bazin podemos decir que son "transferencias de realidad" y, por tanto realidades, o bien, podemos decir que "comparten el ser" con aquello de lo que son huellas.

Para evitar malos entendidos conviene precisar el concepto de transferencia de realidad que estamos utilizando. Podemos decir que se trata de un automatismo puramente natural en la transferencia de un conjunto de propiedades físicas de algo a otro conjunto de propiedades físicas de otra cosa. Se trata de la transferencia de propiedades físicas de acuerdo con ciertas trasformaciones matemáticas de dichas propiedades a, generalmente, otras propiedades también físicas. Esto es siempre el caso de los registros. Por ejemplo, las diferentes temperaturas de dos cuerpos no se registran como diferentes temperaturas del termómetro sino que se registran como diferentes alturas de su columna de mercurio, la presión de un recipiente no se registra en presiones al interior del manómetro sino como grados de deflexión de su aguja. Análogamente, la distancia relativa entre elementos de un referente fotográfico se registra - entre otras varias maneras - como tamaños de dichos elementos sobre la imagen fotográfica. Lo importante, pues, es que un juego o conjunto de

\footnotetext{
${ }^{27}$ Obviamente, el famoso asunto de que el fotógrafo toma una serie de decisiones que determinan el resultado fotográfico no elimina para nada el hecho básico de que lo que opera en la obtención de la fotografía en tanto tal es un mecanismo físico automático.
} 
propiedades físicas de un sistema queda registrado - "mapeado" por una función matemática - por otro juego o conjunto de propiedades fisicas de otro sistema; en otras palabras, un juego de propiedades físicas encontradas en el mundo empírico queda transferido a un objeto dado de dicho mundo - la arcilla fresca, la película fotosensitiva, el sensor digital, el termómetro, el manómetro - como otro juego de propiedades físicas del objeto receptor. Aquí utilizamos el término "sistema" en el sentido que tiene en la teoría física, así, por ejemplo, el cuerpo de la persona es un sistema y el termómetro que registra su temperatura es otro sistema, un automóvil en movimiento y su velocímetro son dos sistemas y, en el caso que nos interesa, el entorno lumínico enfrente de la cámara es un sistema y la cámara misma es otro sistema. Obviamente, si el sistema físico B "registra" las propiedades del sistema físico A, eso quiere decir que ciertas propiedades del sistema B sufren cierto efecto a causa de ciertas propiedades del sistema A, efecto que siempre puede expresarse o modelarse con una función matemática, dado que las legalidades naturales siempre son modelables matemáticamente. Así pues, la transferencia de realidad (Bazin) que nos ocupa aquí no es otra cosa que el efecto expresable matemáticamente de propiedades de un sistema físico (lo registrado) en propiedades de otro sistema físico (el registro). Eso mismo es lo que estuvo en la base de la discusión sobre la transformación de la imagen que hicimos en la segunda parte de este trabajo, así, por ejemplo, la transferencia de las propiedades físicas del objeto que está frente al espejo elongado en la casa de los espejos ocurre de acuerdo con reglas matemáticas y da por resultado la imagen elongada del mismo objeto sobre el espejo. En síntesis, el registro fotográfico análogo o digital del referente es una transferencia de propiedades físicas del referente a propiedades físicas de la fotografía de acuerdo con una legalidad física automática que siempre se puede expresar como una transformación - "función" - matemática. Y esto es lo importante de los registros: la subjetividad no tiene absolutamente nada que ver con la transformación matemática que expresa y modela el automatismo de la transferencia de propiedades físicas de una realidad - un sistema - a otras propiedades físicas de otra realidad - otro sistema -. ${ }^{28}$

Como es claro, en el caso de una pintura la subjetividad, sí es un factor en el resultado constituido por la misma, en las propiedades pictóricas o figurativas de la pintura. Si bien en la producción de una pintura intervienen legalidades físicas, dichas legalidades están entremezcladas con la subjetividad, es decir, ninguna pintura es un resultado automático de puras legalidades naturales - y ni siquiera en el caso del retrato más realista de algo existe la

\footnotetext{
${ }^{28}$ Se sobre entiende que hablamos aquí de registros automáticos.
} 
función matemática que modelaría la transferencia automática de propiedades físicas de lo retratado a su retrato: no existe dicha función por el hecho de que no existe tampoco la transferencia automática en cuestión -. Y lo mismo vale para las imágenes digitales no indéxicas. Estas últimas son resultado de una manipulación digital que está tan ligada a la subjetividad como lo está la acción del pintor sobre el lienzo. Pongamos algunos ejemplos de esto.

Cuando un "animador digital" sintetiza una imagen utiliza, por ejemplo, ciertos "cuerpos" que toma de un menú del programa de animación, y ya la sola posición relativa de los cuerpos en la imagen es un resultado de su subjetividad - por no hablar de muchos otros elementos como la forma que se le puede dar a cada uno de dichos cuerpos -. Ni los cuerpos ni su posición son un registro de nada, no son ninguna transferencia de propiedades físicas o naturales de algo al producto resultante, la imagen sintetizada. Similarmente, cuando un compositor digital de imágenes toma fotografías digitales o sus partes para obtener una imagen nueva, justamente, compuesta, tenemos que el resultado total no es tampoco el registro digital de las propiedades físicas de nada. Finalmente, cuando un diseñador digital utiliza algún instrumento de la "menú" de herramientas de un programa tal como Photoshopdigamos el "clonador", o la "varita mágica", etc. ${ }^{29}$ - para obtener algún resultado sobre la imagen en la que trabaja, la presencia de la subjetividad en el resultado se muestra nuevamente en el hecho de que la imagen final no es, nuevamente, el registro de las propiedades de nada, no es una transferencia de realidad de un referente a la imagen digital. El uso de tales herramientas es, en términos de la cualidad no indéxica y dependiente de la habilidad del animador, una actividad análoga a la del pintor, es decir, da resultados "subjetivos" que no corresponden a ningún registro.

En síntesis, podemos decir que ni la pintura ni los objetos digitales de los que acabamos de hablar son el resultado de la operación automática de legalidades físicas que garantizan una transferencia de propiedades naturales de ninguna cosa a la imagen. Con ello la imagen no está en relación de continuidad ontológica con el mundo natural. Ahora bien, ciertamente una pintura, por ejemplo, o un collage fotográfico digital o la impresión de una composición o una sintetización digitales, son objetos del mundo empírico, pero no como huellas de nada, no registran nada; están insertos en la legalidad natural - por ejemplo, son combustibles, tienen un peso - pero de una manera que no depende en lo absoluto de otra

${ }^{29}$ El "clonador" toma partes de una imagen para transferirlas a otra parte de la imagen, la "varita mágica" toma partes de la imagen para, por ejemplo, eliminarlas o transformarlas cromáticamente. 
realidad empírica, es decir, de una manera que no depende en lo absoluto de aquello que representan.

\subsection{La transferencia de realidad y la transferencia de imaginación}

Para precisar la discusión podemos distinguir aquí entre las propiedades figurativas o icónicas de las imágenes fijas y sus propiedades no figurativas, sean las imágenes indéxicas o no. Tomemos primero el caso imágenes que son iconos indéxicos, es decir, se trata de fotografías - análogas o digitales, da lo mismo -. En este caso, si las imágenes están impresas en papel el peso y el tamaño de la imagen serían propiedades no figurativas o no icónicas, mientras que si se trata de fotografías a color, la gama cromática particular de las mismas y las relaciones entre los objetos mostrados serán propiedades icónicas. Es evidente que las propiedades no icónicas de la fotografía son al mismo tiempo propiedades no indéxicas de las mismas, es decir, no son parte del registro de nada, no son el resultado de la transferencia de propiedades del referente a la fotografía. En otras palabras, solamente las propiedades icónicas de la fotografía son al mismo tiempo sus propiedades indéxicas y, a su vez, solamente las propiedades indéxicas son el resultado de la transferencia automático matemática de propiedades fisicas del referente a la fotografía. Las propiedades icónicas de una fotografía indican las propiedades físicas de su referente - informan sobre ellas -. Esto, por supuesto, no es más que otra manera de decir que una fotografía es un icono indéxico, y ambas cosas no son más que una manera técnica de decir que lo que se reconoce en una fotografía - lo figurativo o icónico de la misma - no es más que el resultado automático de la acción de legalidades naturales.

En el caso de las imágenes fijas no indéxicas - sean estas pinturas tradicionales o composiciones o sintetizaciones digitales - sus propiedades figurativas, por ejemplo su gama cromática, son, ciertamente, propiedades físicas de las imágenes tanto como lo son sus propiedades no figurativas; sin embargo, sus propiedades figurativas o icónicas no son el registro de nado sino la mezcla de legalidades físicas con las habilidades de sus creadores - el pintor tradicional o el creador digital -. Las propiedades figurativas de estas imágenes no solamente no son el resultado automático de legalidades físicas, no solamente no son la transferencia de realidad del mundo empírico a la imagen, de propiedades de dicho mundo a la misma, sino que más bien son la transferencia de la imaginación del creador a la imagen. Podemos decir, entonces que las propiedades icónicas de las imágenes que no son iconos indéxicos no son transferencia de realidad del mundo a la imagen sino que son, estrictamente, 
transferencia de la imaginación del creador a la imagen. La imaginación transferida a las propiedades icónicas de la imagen se convierte, en términos de experiencia estética del receptor de la imagen, en ilusión. Es justamente la imaginación transferida a la imagen como las propiedades figurativas no indéxicas de la misma lo que permite que el observador de la imagen tenga una ilusión. ${ }^{30}$ Cuando en la primera y en la segunda parte de este texto dijimos que a diferencia de las imágenes indéxicas - las fotográficas - las imágenes no indéxicas pertenecen al orden de la ilusión y no al orden de la realidad, lo que estaba atrás de ello es que las imágenes no indéxicas son transferencia de imaginación a propiedades figurativas, mientras que las imágenes indéxicas son transferencia de realidad a propiedades figurativas. Así, los íconos indéxicos son registros de propiedades físicas del mundo empírico mientras que los iconos no indéxicos son la transferencia de la imaginación de su creador al mundo empírico, la plasmación plástica de la imaginación o, si se prefiere, el producto de la imaginación plástica. Por ello, resulta conveniente complementar la tesis de que la pintura y la imagen digital fija no indéxica pertenecen al mundo de la ilusión, con la tesis de que pertenecen al mundo de la imaginación plástica, de la imaginación materializada icónicamente - con esto se cubre tanto el fenómeno del creador como el del receptor, los cuales son fenómenos estrictamente complementarios -. Esta intrusión de la imaginación en la realidad empírica, que se da como la muy peculiar estructura que aúna propiedades no figurativas con propiedades figurativas provenientes de la imaginación, es lo que hace de las imágenes no indéxicas objetos empíricos que no pertenecen puramente al mundo empírico sino que son, intrusiones de la imaginación en dicho mundo empírico, como transferencia de la imaginación a propiedades figurativas que, obviamente, son empíricas - siguiendo la terminología de Barthes, podríamos decir que mientras que la fotografía es una emanación de la realidad, la pintura - de hecho, la imagen no indéxica en general - es una emanación de la imaginación como intrusión en la realidad.

\subsection{La conexión física y la imaginación}

Se podría pensar que los recién discutido es válido en el caso de imágenes no indéxicas que representan cosas fantásticas, por ejemplo a Pegaso, pero que en otros casos la discusión sobre la plasmación plástica de la imaginación no es válida. Tomemos lo que parece ser el caso más problemático para la argumentación desarrollada arriba, a saber, el del retrato. Consideremos por ejemplo el retrato histórico de Enrique VIII, rey de Inglaterra, de quien

\footnotetext{
${ }^{30} \mathrm{Y}$ esto vale también para el retrato más realista, según veremos abajo.
} 
existen múltiples retratos, y lo cierto es que los dos retratos de él elaborados por Hans Holbein el Joven y el atribuido a Joos van Cleve muestran verdaderamente un gran parecido entre sí. El hecho es entonces que podemos decir, en términos coloquiales, que los tres retratos nos informan sobre el aspecto del monarca: como se ve en los retratos es como debe de haberse visto. El concepto “información” es importante aquí porque, precisamente, dado el mapeo matemático que modela la transferencia de un conjunto de propiedades empíricas de una realidad a las propiedades empíricas de otra realidad, el segundo conjunto de propiedades nos informa sobre las propiedades, del primer conjunto. Así, por ejemplo, los tamaños relativos de los objetos reconocibles en una fotografía pueden informarnos sobre las distancias relativas de dichos objetos en la realidad. Por ello, si un retrato pictórico nos informa sobre el aspecto del modelo parecería, entonces, a primera vista que no tiene una gran diferencia respecto de cualquier icono indéxico, el cual, como todo índice, es portador de información. En otras palabras el "registro" pictórico del aspecto de una persona parece ser algo muy similar al registro fotográfico de la misma en tanto portador de información sobre la apariencia de la persona. En este punto es interesante recurrir a una notabilísima e importante idea de Peirce, a saber, el carácter de un signo como "aplicación demostrativa pura" (WP 67).

Un signo posee el carácter de "aplicación demostrativa pura", nos dice Pierce, cuando está en una “conexión causal real con la cosa por el significada” (WP 67). Ahora bien, lo interesante de esta idea es que según Peirce “(...) tiene que existir tal conexión entre todo signo y su objeto." (WP 66) En otras palabras todo lo que verdaderamente sea un signo tiene el carácter de "aplicación demostrativa pura". Exactamente a continuación Peirce nos trata de explicar cómo existe tal "conexión causal real" justo entre el retrato de una persona y la persona en cuestión:

"Tomemos un retrato pintado. Es el signo de la persona que se pretende. Es un signo de esa persona en virtud de su semejanza con esa persona, pero esto no es suficiente - no se puede decir de cualesquiera dos cosas que son parecidas que una es un signo de la otra, pero el retrato es signo de esa persona porque fue pintado según esa persona y la representa. La conexión es aquí indirecta. La apariencia de la persona produjo cierta impresión sobre la mente del pintor y actuó para causar que el pintor hiciera la pintura como la hizo, de manera tal que la apariencia del retrato es un efecto de la apariencia de la persona que se pretendió. Una causó la otra a través de la mente del pintor." (WP 66s.)

En otras palabras, el retrato tiene el carácter de "aplicación demostrativa pura" en la medida en la que "significa" la persona retratada no porque se parezca a ella sino gracias a una 
"conexión física" con ella, aunque esta conexión sea "indirecta", nos dice Peirce, "a través de la mente del pintor". Como es evidente, esto concuerda muy bien con la idea adelantada arriba de que un retrato bien logrado - "según” la persona -, proporciona información sobre la persona, como también lo haría el índice fotográfico de dicha persona. Reformulando el razonamiento de Pierce podríamos decir que el retrato es un índice pictórico de la persona que a través de la mente del pintor está en conexión física con la persona. ${ }^{31} \mathrm{Si}$ queremos seguir el razonamiento de Peirce, el cual, de hecho, amplía el concepto de índice, aún podremos decir que entre la "conexión física" que el índice pictórico - el retrato, en este caso - tiene con la persona retratada, por un lado y, por otro, la conexión física que existe entre la fotografía y la persona fotografiada, la diferencia fundamental es que no existe ninguna función matemática que modele la transferencia de la información sobre la persona - las propiedades físicas que constituyen su apariencia - a las propiedades figurativas del retrato pictórico. En otras palabras, aún si aceptamos está ampliación de facto que Peirce hace del concepto de índice, por lo menos en el caso del retrato tendríamos que decir que por la ausencia del mapeo matemático que modele la transferencia puramente objetiva de propiedades de la persona a propiedades del retrato pictórico, tendríamos un índice en un sentido débil que difiere del concepto de índice en el sentido fuerte de un registro automático de propiedades de una realidad como propiedades de otra realidad. ${ }^{32}$

En este contexto la noción de información es importante y queda claro que el índice siempre es portador de información sobre lo que indica. Así, por ejemplo, la veleta informa sobre la dirección del viento, los gansos volando hacia el sur informan sobre, es decir, indican la proximidad del invierno; la charca congelada informa, es decir, indica que la temperatura no sobrepasa los cero grados centígrados y, por supuesto, tal es el caso de todos los aparatos de registro ideados por el hombre. En todos estos casos se trataría de índices en el sentido fuerte del término, de hecho, en el sentido de la definición original de Peirce: “(...) existen las indicaciones o índices, los cuales muestran [informan] algo acerca de cosas porque están

\footnotetext{
${ }^{31}$ Por supuesto, el aspecto temporal no importa aquí: no porque el pintor deje de trabajar en el retrato deja de existir la conexión causal "indirecta" que se estableció entre la persona y su retrato. El análogo de esto es que no porque deje de existir la película o la cámara fotográfica, la fotografía revelada de la persona deja de estar en conexión física con la persona de la cual es fotografía.

${ }^{32}$ Unas pocas líneas arriba hicimos una salvedad cuando dijimos "por lo menos en el caso del retrato"; esto se debe a que la idea peirceana del carácter de "aplicación demostrativa pura" de todo signo es, en verdad, muy amplia y deja abiertas cuestiones complejas tales como si una obra de ficción literaria tiene tal "aplicación", la cual requiere una "conexión física" con el significado de la obra. Si no la tiene, entonces tal obra no es signo de nada - simplemente sus palabras y oraciones no son signos - y si la tiene la pregunta es con qué. Si se dice que con las ideas de la ficción, entonces resulta una conexión física o causal muy extraña entre la mente y las ideas. En fin, problemas como este caen fuera del alcance de nuestro trabajo presente.
} 
conectadas fisicamente con ellas." (EP2 7) Esta idea queda aún más clara cuando Peirce nos dice que "[1]as pinturas solas - semejanzas puras - nunca portan ni la más mínima información.” (EP2 7) Un pintura por sí sola deja abierto, en efecto, “(...) si se trata de una copia de algo que realmente existe o de un mero juego de la fantasía." (EP2 7) Pero resulta claro que el hecho de que la "semejanza", es decir, la imagen icónica, realmente porte información, hace que dicha semejanza deje de ser "un mero icono" (EP2 8) y obtenga el "carácter añadido de un índice" (EP2 8). Aplicando esto al caso del retrato discutido arriba, fue la apariencia del modelo lo que definió "(...) cómo fue afectado el artista mismo (...)" (EP2 2) por lo que, nos dice Peirce, “(...) la apariencia del retrato es un efecto de la apariencia de la persona (...)" (WP 67) - el retrato es "según" la persona -. Dichas afecciones y efectos - de la apariencia de la persona sobre la mente del pintor y de esta sobre el retrato pictórico no son arbitrarios, están en cierta relación de causalidad entre sí - la cual es concebida por Peirce como "conexión física" aunque sea "indirecta", "a través de la mente del pintor" -, por lo que el retrato realmente porta información sobre la persona retratada. Independientemente de la argumentación de Peirce esto concuerda con la experiencia de que un retrato pictórico bien logrado realmente informa sobre la apariencia de la persona retratada, por lo que en un sentido amplio se puede considerar a dichos retratos como índices, a diferencia de las creaciones del "mero juego de la fantasía" (EP2 7).

Pues bien aún así, y concordando con lo que Peirce y el sentido común dicen acerca del retrato como portador de información sobre la persona retratada, lo cierto es que el retrato pictórico siempre es una ilusión acerca del aspecto de la persona, mientras que la fotografía de la persona no lo es nunca. Esto queda claro ya con la confianza que otorgamos a la fotografía como portadora de información la cual es en principio total, mientras que al retrato pictórico por sí mismo nunca la otorgamos dicha confianza, e insistimos en ello: nunca. Puede ser que la fotografía sea deficiente, que la persona no aparezca claramente, sin embargo, eso es falta de información, información insuficiente, pero queda claro que es, de todos modos, información y, en tanto tal, es perfectamente válida. Supongamos el ejemplo rebuscado pero ilustrativo de que la fotografía de una persona solamente muestra la parte superior de su rostro. En este caso falta información respecto de la parte inferior, pero lo que la fotografía muestra corresponde al modelo fotográfico, está fuera de duda: podremos desconocer el aspecto de la parte inferior del rostro de la persona pero estamos plenamente informados sobre el aspecto de la parte superior de su rostro. Otro caso sería el de una fotografía borrosa, la información que otorga es mala no porque sea falsa sino porque es insuficiente, por 
ejemplo para saber a ciencia cierta cómo se ve la persona; pero en este caso no dudamos de la información que nos da la fotografía sino que sabemos que es insuficiente para reconocer a dicha persona. En otras palabras, la virtud o carácter básico de la fotografía como índice - es decir como algo que verdaderamente está en conexión física con su “objeto" - y, por tanto, como portadora de información, nunca está en duda. Usando la terminología peirceana podemos decir que nunca está en duda que una fotografía tenga el carácter de una "aplicación demostrativa pura". De hecho, como ya lo discutimos en la segunda parte de este trabajo, una fotografía, por definición, nunca es una imagen manipulada, la cual ya no tiene carácter de índice. Por eso, mientras que no se tenga ninguna duda acerca de que la fotografía es realmente una fotografía y no una imagen manipulada, su calidad de ser portadora de información está fuera de todo cuestionamiento. Obviamente la situación respecto del retrato pictórico es totalmente distinta.

En el caso de Enrique VIII de manera casi imperceptible introdujimos un elemento fundamental para pensar en cualquiera de los tres retratos mencionados - los dos elaborados por Hans Holbain el Joven y el atribuido a Joos van Cleve - como un verdadero portador de información acerca del aspecto del monarca, a saber, dado que los tres retratos se parecen entres sí tomamos esto como una evidencia de que cualquiera de ellos es un retrato bien logrado. ${ }^{33}$ Supongamos por un momento que solo existiera uno de esos retratos. ¿Qué fundamento tendríamos para pensar que el retrato está bien logrado y que, por consiguiente, nos informa acerca del aspecto del monarca? Absolutamente ninguno. La situación es aún más clara si suponemos que no sabemos quién es el modelo de un retrato dado; de hecho, en este caso ni siquiera podemos estar seguros de que la imagen es un retrato y no el resultado de, como dice Peirce, "un mero juego de la fantasía” (EP2 7). Aquí vale exactamente la afirmación ya citada del propio Peirce en el sentido de que “““[1]as pinturas solas (...) nunca portan ni la más mínima información." (EP2 7) Como dijimos arriba siguiendo a Peirce: una pintura por sí sola deja abierto, en efecto, “(...) si se trata de una copia de algo que realmente existe o de un mero juego de la fantasía." En el caso que nos ocupa, el de los retratos de Enrique VIII no tenemos "una pintura sola" sino varías pinturas apoyándose entre sí - a más del apoyo de documentos escritos sobre dichos retratos -. La situación resulta por demás clara cuando la comparamos con el problemático caso de La Gioconda, de Leonardo da Vinci, ya que en este caso no está probado en lo absoluto que se trate de un retrato, es decir, ni siquiera

${ }^{33}$ Por supuesto, hay otras evidencias constituidas por todas las fuentes escritas que de alguna u otra manera se refieren a los retratos como bien logrados. 
se sabe si hubo una modelo para el cuadro o el mismo es un resultado del "mero juego de la imaginación", y es que en este caso, la pintura se encuentra realmente sola dado que no hay fuentes fidedignas acerca de la naturaleza de la imagen. ${ }^{34}$ De hecho, en gran parte la fama de esta la pintura reposa en el misterio de su naturaleza, en la oscuridad que la rodea.

\subsection{La diferencia ontológica entre imaginar y registrar}

Queda claro entonces, que el retrato histórico necesita de elementos adicionales que, primero, confirmen que es un retrato $\mathrm{y}$, segundo, confirmen que está bien logrado. Sin estas dos condiciones su carácter como portador de información es totalmente incierto - que es el caso de La Gioconda -. Pero aún suponiendo que se cumplen las dos condiciones señaladas, el retrato sigue sin tener con su modelo una relación expresada por una función matemática, es decir, no existe una transferencia plenamente objetiva y automática de las propiedades que definen la apariencia del modelo a las propiedades figurativas de la imagen y que la hacen un retrato. En la relación entre el retrato fotográfico y su modelo solamente hay dos dimensiones: lo que se registró y lo que no se registró. En la relación entre el retrato pictórico y su modelo hay lo que el pintor quiso y pudo pintar y lo que no quiso o no pudo pintar, dadas sus preferencias y sus habilidades. Lo que el pintor pudo y no pudo pintar es un asunto que escapa al automatismo de la operación de las legalidades naturales en los registros, mientras que lo que pintor prefirió o no prefirió pintar es un asunto de su imaginación, la cual escapa a la objetividad de la operación de las legalidades naturales propias de los registros. Lo que el pintor pinta no es meramente lo que ve sino cómo imagina lo que ve y cómo pinta lo que imagina. En síntesis, lo que el pintor documental pinta es su visión pasada por su imaginación y su imaginación pasada por su habilidad. Por eso una pintura sola "nunca porta ni la más mínima información", es decir, siempre queda abierta a si porta o no porta información, mientras que toda fotografía, por su propia naturaleza, siempre porta información.

El pintor documental - y su prototipo es, justamente, el retratista - es aquel que minimiza el papel de su imaginación en la pintura, como también lo hace el pintor fotorealista, sin embargo, en ambos casos la imaginación está presente en la pintura que brota de sus trazos, por lo que el observador de la obra siempre está frente a una ilusión: frente a la transferencia de la imaginación del pintor a la pintura. Por el contrario, el observador de una fotografía siempre está frente a una realidad: frente a la realidad transferida de lo fotografiado

\footnotetext{
${ }^{34}$ Existe la tesis de que sí hubo una modelo y que era la esposa de Francesco Bartolomeo del Giocondo, pero se trata hasta ahora de una mera hipótesis.
} 
a la fotografía. Pero esto significa que la realidad de la pintura es, siempre, en todos los casos, un híbrido de realidad empírica que porta la imaginación que produce ilusión. Se trata de la imaginación plástica (del pintor) plasmada en realidad empírica (de la obra) y que solamente así es capaz de producir ilusión (en el observador). Esta compleja estructura ontológica de la pintura también es propia de la imagen digital no indéxica y es radicalmente diferente del tipo de realidad propio la imagen indéxica, la imagen fotográfica, ya sea análoga o digital, la cual nunca es ilusión por ser un duplicado o huella del mundo. En el caso de la imagen digital no indéxica - no fotográfica -, la compuesta y la sintetizada, la ilusión no es pictórica sino tecnológica, lo cual significa en general que la ilusión de una categoría superior debido a su intensidad, intensidad que en sí es una cualidad: la "impresión de realidad" (Metz). ${ }^{35}$

Podemos decir, pues, que mientras que la fotografía o imagen indéxica fija - análoga o digital - es una realidad del mundo empírico, la imagen fija no indéxica - pictórica y digital es una realidad del mundo de la imaginación y de la ilusión que es portada por una realidad empírica.

\section{Bibliografía y abreviaturas}

$\mathrm{CL}=$ Barthes, R., Camera Lucida, Reflexions on Photography, Farrar, Strauss, and Giraux, New York, 1982.

WC1 = Bazin, A., What is Cinema? Vol. 1, University of California Press, California, 2005.

WC2 = Bazin, A., What is Cinema? Vol. 2, University of California Press, California, 2005.

MA = Bordieu, P., et al, Photography. A Middle-brow Art, Polity Press, Cambridge, 1998.

VD = Darley, A., Visual Digital Culture. Surface Play and Spectacle in New Media Genres, Routledge, New York, $\mathrm{AF}$ = Dubois, P., El acto fotográfico. De la representación a la recepción, Paidos, Barcelona, 1983.

FL = Metz, C., Film Language. A Semiotics of the Cinema, The University of Chicago Press, Chicago 1991.

\footnotetext{
${ }^{35}$ Teniendo en mente la base fotográfica del cine (cfr. FL 15), Christian Metz habla de la "impresión de realidad en el cine" (FL, 6); apoyándonos en él podríamos decir que la intensidad de la ilusión tecnológica es tal que a diferencia de la ilusión pictórica la ilusión tecnológica realmente genera una impresión de realidad, cosa que en el caso pictórico nunca se da. Nótese que el engaño propio del trompe l'oeil no es una impresión de realidad en el sentido de Metz, ya que la expresión de Metz utiliza el término "impresión” justamente porque el espectador cinematográfico sabe que lo que ve no es un reportaje de un hecho real sino que solamente se trata de cine, mientras que quien sucumbe al trompe l'oeil verdaderamente cree estar viendo algo real y no una mera imagen. Por supuesto, en un sentido más amplio y menos técnico, se puede decir que el trompe l'oeil es una impresión de realidad, como también lo son, por ejemplo, muchas ilusiones ópticas. Por mor de la completitud señalemos aquí que a pesar de interesarse por el cine y en relación con él discutir la fotografía, Metz utiliza el término impresión de realidad también en el sentido de "ilusión" tal como manejamos aquí este término, por eso se refiere a los diferentes grados de la impresión de realidad según se trate del cine, la fotografía, el teatro, la escultura, la pintura y el dibujo figurativos (cfr. FL 6).
} 
Yueva Tinexaxia ORevista OSigital de Silosofrar ISSN 1850-3578

EP = Peirce, Ch. S., The Essential Peirce. Selected Philosophical Writings (1893-1913), Vol. 2. Indiana University Press, Bloomington, 1998.

WP = Peirce, Ch. S., Writings on Semiotic, University of North Carolina Press, Chapel Hill 1991. 